\title{
Hibridismo lingüístico en la Vasconia peninsular: influjo de la lengua castellana en la lengua vasca ${ }^{1}$
}

\author{
Karlos Cid Abasolo \\ (UCM) \\ abasolo@filol.ucm.es \\ Recibido: marzo de 2014. Aceptado: mayo de 2014
}

\begin{abstract}
RESUMEN: Este artículo es continuación del que publicamos en el número anterior de esta revista: en aquel tratamos el tema de la influencia del vascuence en el español hablado en la Vasconia peninsular. En esta ocasión nos centramos en la influencia inversa, es decir, la del español en el vascuence, mucho mayor dada la situación de diglosia que vive dicho territorio. Tal influencia afecta, lógicamente, a todos los niveles de lengua, y se ha acentuado en los últimos años debido a razones sociolingüísticas, en particular, al cambio del perfil mayoritario de los bilingües: en el pasado, eran mayoría los que tenían el vasco como lengua materna y el español como segunda lengua, pero, con la implantación de la enseñanza del vasco y en vasco en zonas hasta ahora monolingües en español, entre los bilingües han pasado a ser mayoría aquellos que tienen el español como primera lengua y el vascuence como segunda.
\end{abstract}

PALABRAS CLAVE: vascuenzol - euskañol - diglosia - lenguas en contacto - alternancia de códigos

\begin{abstract}
This article is a continuation of that published in the previous issue of this review: in that article we dealt with the influence of Basque in the Spanish spoken in the peninsular Basque Country. On this occasion, we focus on the reverse influence, namely, that of Spanish on Basque, much higher given the situation of diglossia in that territory. Logically, such influence affects all levels of language, and has increased in recent years due to sociolinguistic reasons, in particular, the change in the predominant profile of bilinguals: in the past, those having Basque as a native language and Spanish as a second one were a majority, but since the implementation of teaching of Basque and in Basque in hitherto monolingual Spanish areas, among bilinguals
\end{abstract}

1 En este artículo utilizaremos indistintamente las expresiones lengua castellana, lengua española, castellano y español. Asimismo, para no incurrir en el espacuence (Cid Abasolo: 2013), evitaremos los términos euskera y euscaldún o euskaldún (recogidos, no obstante, en el DRAE), optando por las palabras vasco (así como lengua vasca, vascuence y éuscaro) y vascohablante. 
those who have Spanish as their first language and Basque as a second one have become mainstream.

KEY WORDS: basquespanish - diglossia - contact languages - code switching

En la Vasconia peninsular ${ }^{2}$, y en contra de lo que suele pensarse, no se habla, en un sentido estricto, español y vasco, sino lo que en un trabajo anterior (Cid Abasolo: 2013) denominamos espacuence (mayoritario y definible como español con aderezos de vascuence) y lo que aquí denominaremos vascuenzol (vasco con múltiples elementos del español) ${ }^{3}$. Ambos híbridos se caracterizan por interferencias de una lengua en todos los niveles (fonético, morfológico, sintáctico, léxico) de la otra, interferencias que pueden ser o no causa de agramaticalidad. Dos de las más importantes son el préstamo y la alternancia de códigos. En ocasiones resulta difusa la frontera entre ambos. El criterio que seguiremos en este trabajo es el siguiente: consideraremos alternancia de códigos en el vascuenzol aquellos casos en los que el transvase no solo tiene carácter léxico, sino también morfológico (v.gr., uso del plural castellano) y sintáctico. Veamos un ejemplo que esperamos resulte esclarecedor. Dadas las oraciones:

a) Rock-talde horren diskoak dira... muy potentes

b) Rock-talde horren diskoak oso potenteak dira

c) Rock-talde horren diskoak oso potentiak dira

d) Rock-talde horren diskoak oso potentiek dire

Las cuatro significan «Los discos de esa banda de rock son muy potentes», y en las cuatro se ha empleado el préstamo léxico potente. La diferencia estriba en que la primera variante es un caso de alternancia de códigos, ya que en el atributo «muy potentes» no solo hay calco léxico (potente), sino también dos calcos morfosintácticos (anteposición del adverbio muy, y morfema de plural $-s$ ). En cambio, en b), c) y d) no hay alternancia de códigos porque el préstamo se ha incorporado a las características fonéticas y morfológicas del vasco:

- Se le ha añadido el artículo vasco - $a$ y el morfema de plural $-k$.

- En c), además, se ha producido la siguiente disimilación, propia de diversos dialectos y subdialectos vascos: potenteak $\rightarrow$ potentiak $(\mathrm{e} \rightarrow \mathrm{i} / \ldots$ a). $\mathrm{e} / \mathrm{i}$

- En d), se ha producido la siguiente asimilación a partir de potentiak: a $\rightarrow$

Resulta imposible describir exhaustivamente el vascuenzol en un artículo. El secular contacto entre las lenguas vasca y castellana y la situación de diglosia que aquella ha sufrido y sufre respecto a esta han provocado numerosísimas interferen-

2 En adelante, VP. La forman la Comunidad Autónoma Vasca (en adelante, CAV) y la Comunidad Foral de Navarra (en adelante, CFN).

3 En la Vasconia continental (en adelante, VC), es decir, el País Vasco francés, ocurre lo mismo entre el éuscaro y el francés (Epelde \& Oyharçabal: 2003). No obstante, en este artículo nos centraremos en el hibridismo lingüístico de la VP, concretamente, en el vascuenzol. 
cias, por lo que nos limitaremos a centrarnos en las más relevantes. De cada aspecto de la lengua mencionaremos solo algunos ejemplos. Trataremos de que las explicaciones sean comprensibles incluso para quienes no saben nada de vasco.

Más conocidos que espacuence y vascuenzol son los neologismos euskañol y vascoñol, que suelen utilizarse indistintamente en el sentido de espacuence y vascuenzol, lo cual no parece muy adecuado al tratarse de dos realidades distintas. Nosotros preferimos hacer una diferenciación léxica, al tratarse de híbridos en direcciones contrarias (influencia del vasco en el español vs. influencia del español en el vasco). En cualquier caso, hay que precisar que ninguno de los cuatro vocablos están recogidos en los diccionarios: los dos primeros han logrado una cierta raigambre, incluso en ámbitos universitarios, y los otros dos son propuestas nuestras sin recorrido previo. Nosotros no somos partidarios de recurrir al término euskañol porque el empleo de la palabra euskera en español, aunque haya sido aceptada en el DRAE, no deja de ser un rasgo más de espacuence. Y, en cierta medida, es el espacuence uno de los factores que han impedido e impiden un mayor uso de la lengua vasca. El espacuence es un rasgo más de la idiosincrasia de la VP. Es más: es un rasgo más idiosincrático de la VP actual que la propia lengua vasca. Para los vascos no vascohablantes, intercalar en su español un puñado de palabras vascas resulta mucho más cómodo que aprender vasco. No obstante, conviene recordar que muchos de ellos, en lugar de instalarse en la comodidad, lo han aprendido. Y lo hablan.

Por las razones expuestas, nosotros recurriremos a las mencionadas expresiones espacuence ( 31 resultados en Google hasta la fecha, merced a una conferencia y a un artículo nuestros) y vascuenzol (0 resultados en Google, cosa que cambiará cuando este artículo sea publicado).

Todos los ejemplos de textos orales que vamos a aportar han sido extraídos de la radio y televisión públicas en lengua vasca de la CAV: Euskadi Irratia y ETB1.

\section{FONÉTICA Y ACENTO}

Algunos elementos fonéticos del español se han incorporado al vasco hablado en la VP. He aquí algunos ejemplos:

a) yeísmo. $[\lambda]>[\mathrm{y}]$. Ejemplos: mutila ('el chico'), bonbilla, etc., con deslateralización de la consonante lateral. Este fenómeno panhispánico se inició en la lengua vasca a raíz de la puesta en marcha de iniciativas de euskaldunización. Los castellanohablantes que aprenden vasco, al ser yeístas en su lengua materna, también lo son, en su mayoría, cuando hablan vasco. El yeísmo empieza a detectarse también en las nuevas generaciones de vascos que tienen el éuscaro como lengua materna.

b) ceceo. $[\mathrm{s}]>[\theta]$. En préstamos y apellidos. Recordemos que el fonema interdental fricativo sordo del español no existe en vasco, que tiene como equivalente el fonema sibilante predorsal fricativo sordo. En préstamos, sin embargo, suele pronunciarse la consonante interdental en perjuicio de la predorsal. Ejem-

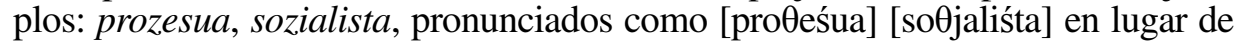


[proseśua], [sosjaliśta]. Lo mismo ocurre en apellidos como Linazasoro (pronunciado en vasco por muchos hablantes como [Linaقaśoro] en lugar de [Linasaśoro]), lo cual puede explicarse por la marginación del vascuence de los ámbitos oficiales hasta la implantación del Estatuto de Gernika. Los apellidos forman parte de esa oficialidad, y no olvidemos que, a pesar de que la legislación actual permite la grafía vasca tanto en nombres como apellidos vascos, muchos ciudadanos de la VP (y, obviamente, de fuera de ella) mantienen la grafía castellana en sus apellidos (Echevarría, Echegoyen, etc.). En el ejemplo que hemos traído a colación, Linazasoro, no hay diferencia ortográfica, pero si fonética. Y la pronunciación del grafema $<\mathrm{Z}>$ como interdental en apellidos vascos es otra prueba más del peso de la costumbre y de que no se ha completado la oficialidad de la lengua vasca.

c) en vasco de la VP el acento suele recaer en la segunda sílaba (con un acento secundario en la sílaba final), y en castellano en la penúltima. Muchos vascohablantes acentúan según la tendencia castellana. El influjo es particularmente común en la pronunciación de apellidos vascos (Arizkorréta, Linazasóro, etc., en lugar de Arízkorretà, Linázasorò, etc.), pero también se detecta en sustantivos (harrotasúna 'orgullo', en lugar de harrótasunà). Así pues, en la pronunciación habitual de los dos apellidos vascos mencionados encontramos dos elementos del español: el acento y la consonante interdental.

d) el acento de los adjetivos posesivos prenominales: en vasco son tónicos (niré etxeà), en tanto que, en español, son átonos (mi cása), a no ser que sean el foco (esta es mí cása). La interferencia consiste en convertir en átono el adjetivo posesivo vasco (nire etxéa).

e) el acento del adverbio negativo (ez): en vasco es átono (ez dút 'no lo tengo'). En español, tónico (nó lo téngo). La interferencia consiste en que el adverbio vasco sea tónico, con acento propio (éz dút).

\section{MORFOSINTAXIS}

a) en vasco hay cuatro paradigmas de número (singular, plural lejano, plural cercano, e indefinido), frente a los dos del español (singular y plural). Muchos hablantes, por interferencia de español, aplican el singular en lugar del indefinido. Ejemplo: en la canción Lau teilatu 'Cuatro tejados', del grupo Itoiz, escuchamos *edozein herriko jaietan ('en las fiestas de cualquier pueblo') en lugar de la expresión correcta edozein herritako jaietan. El adjetivo indefinido edozein ('cualquier') exige el paradigma de número indefinido para el sustantivo (sufijo -tako, indefinido, frente a - $k o$, que es singular).

b) en vasco, salvo algunas excepciones, no hay distinción de género en nombres y adjetivos. Irakasle significa tanto profesora como profesor. El problema es que muchos préstamos han llegado procedentes del español, que en sustantivos y adjetivos suele marcar el género (-o vs. $-a$ ). La Real Academia de la Lengua Vasca (en adelante, RALV) estableció como base la forma masculina (piloto, biologo), tanto para el valor masculino como para el femenino: biologo significa, pues, tanto biólogo como bióloga. Sin embargo, muchos vascohablantes, siguiendo el patrón del español, y al ver en el morfema - $o$ una evidente 
marca de género, sí marcan la diferencia genérica [Ane biologa da, en lugar de Ane biologoa da (Ane es bióloga)]. En la literatura vasca, los diálogos (lógicamente, pegados al habla real) nos ofrecen múltiples ejemplos ${ }^{4}$. Así pues, el criterio de la RALV no es secundado en la lengua hablada.

No obstante, hay que señalar que en algunos dialectos vascos (bajo-navarro, suletino, y el extinto roncalés) ha habido tendencia a marcar el género femenino en algunos sustantivos mediante el sufijo indoeuropeo -sa (alkate 'alcalde' vs. alkatesa 'alcaldesa'; aktore 'actor' vs. aktoresa 'actriz'; alargun 'viudo' vs. alarguntsa 'viuda'). Sin embargo, dicha distinción no ha sido recogida en la lengua vasca unificada, en la cual alkate, aktore o alargun se aplican indistintamente a hombres y mujeres.

c) la preposición castellana de es polisémica. Cuando es traducida a otras lenguas románicas, la equivalencia es obvia ya que estas cuentan con una preposición similar. El problema se plantea cuando se busca su equivalencia en lenguas no románicas. Su traducción al vasco depende de su significado: morfema - $k o$ si es genitivo-locativa, -en si es posesiva, y ausencia de caso en nombres compuestos. Los neo-vascohablantes con escasa competencia lingüística suelen cometer el error de no elegir la forma vasca correcta para cada caso. Ejemplos: para 'servicios de limpieza', son incorrectas las expresiones *garbiketako zerbitzuak y * garbiketaren zerbitzuak. La correcta es garbiketa zerbitzuak, sin añadir a garbiketa terminación alguna, tal como ocurre, por ejemplo, en la expresión inglesa equivalente cleaning services.

d) colocación de la aposición respecto al nombre: en vasco, la aposición aparece a la izquierda. Ejemplo: Aranburu harategia ('carnicería Aranburu'). En no pocas rotulaciones y anuncios de establecimientos la encontramos a la derecha (*harategia Lizundia), por influencia del español.

e) en los verbos vascos encontramos las siguientes marcas nominales: de sujeto $\%$ objeto directo (correspondiente al caso absoluto), de agente ${ }^{6}$ (correspondiente al caso ergativo) y de objeto indirecto (correspondiente al caso dativo). Como es sabido, en las lenguas indoeuropeas solo hay marca del sujeto/agente. Por influencia del castellano, los neo-vascohablantes con escasa competencia lingüística en vasco suelen cometer el error de no incluir el morfema de objeto directo plural (it o $z$ ) en el verbo. Ejemplo: *sagarrak erosi dut 'he comprado manzanas', en lugar de sagarrak erosi ditut 'he comprado manzanas'.

f) uso de la rección ERGATIVO-ABSOLUTO-DATIVO en lugar de la rección ERGATIVO-ABSOLUTO. Puede achacarse a la coincidencia formal, en español, de ciertos clíticos en las funciones de objeto directo y objeto indirecto (me, te, nos, os). Ejemplo: ikusi dizut en lugar de ikusi zaitut 'te he visto'. El auxiliar dizut tiene marca de ergativo $\left(t, 1^{\mathrm{a}} \mathrm{s}\right.$. $)$, dativo $\left(z u, 2^{\mathrm{a}} \mathrm{s}\right.$.) y absoluto $\left(3^{\mathrm{a}} \mathrm{s}\right.$.). Ikusi dizut significa, pues, literalmente, «te lo he visto», si bien algunos hablantes lo utilizan también con el sentido de «te he visto». Este error lo cometen

\footnotetext{
«Ea guapa jartzen zaren» 'A ver si te pones guapa', Katixa Agirre, Habitat, Elkar, 2009, 145.

Es decir, sujeto de verbo intransitivo.

Es decir, sujeto de verbo transitivo.
} 
neo-vascohablantes con escasa competencia lingüística en vasco, así como algunos vascohablantes nativos.

g) uso de la rección ERGATIVO-ABSOLUTO en lugar de la rección ERGATIVO-ABSOLUTO-DATIVO en verbos con ABS referencial. Puede achacarse, tal como ocurría en la interferencia anterior, a la coincidencia formal, en español, de ciertos clíticos en las funciones de objeto directo y objeto indirecto (me, te, nos, os). Ejemplo de José María Iparraguirre (siglo XIX): Zibilak esan naute (...) ('Los civiles me han dicho (...)'). El auxiliar naute tiene marca de ergativo (te, $3^{\mathrm{a}} \mathrm{pl}$.) y absoluto ( $n, 1^{\mathrm{a}} \mathrm{s}$.). Lo correcto habría sido esan didate (ERG $3^{\mathrm{a}}$ pl., DAT $1^{\mathrm{a}}$ s., ABS $3^{\mathrm{a}}$ s.), pues el verbo esan ('decir'), en este ejemplo, tiene tres argumentos. Este error lo cometen neo-vascohablantes con escasa competencia lingüística en vasco, así como algunos vascohablantes nativos.

h) uso de la rección ERGATIVO-ABSOLUTO en lugar de la rección ERGATIVO-ABSOLUTO-DATIVO EN VERBOS CON ABS no referencial. Hay algunos verbos que, aunque morfológicamente sean de triple rección (ABS-DAT-ERG), solo tienen dos argumentos. El tema corresponde al morfema verbal de dativo, de modo que la marca de ABS, siempre en tercera persona del singular, no es referencial. No es, pues, de extrañar que haya hablantes que para estos verbos empleen la rección ABS-ERG, vinculando la morfología a la semántica. Ejemplo: *eutsi dut (ERG1 ${ }^{a}$ s., $\mathrm{ABS}^{\mathrm{a}}{ }^{\mathrm{s}}$ s.) en lugar de eutsi diot ('lo he agarrado', ERG1 a s., ABS3 ${ }^{a}$ s., DAT3 ${ }^{a}$ s.).

i) uso de la rección ABSOLUTO-DATIVO en lugar de la rección ABSOLUTO. Ello ocurre con verbos vascos cuyos correspondientes españoles son pronominales en español (despertarse, levantarse, etc.), cuyo pronombre es interpretado como dativo. Este error lo cometen neo-vascohablantes con muy escasa competencia lingüística.

j) uso del presente en ofrecimientos y peticiones: *Irekita uzten dut atea? (literalmente, ‘dejo la puerta abierta?'; *Atea irekitzen duzu, mesedez? (literalmente, ' ¿abres la puerta, por favor?'). Lo correcto en estos casos es el uso, entre otras posibilidades, del futuro: Irekita utziko dut atea? (literalmente, '¿dejaré la puerta abierta?'); Atea irekiko duzu, mesedez? (literalmente, '¿abrirás la puerta, por favor?').

k) uso del potencial en peticiones: Pasa zeniezadake ogia, mesedez? (literalmente, ¿podrías pasarme el pan, por favor?). No es que se trate de una expresión agramatical, pero, en estos casos, lo natural resulta el uso del futuro o del imperativo: Pasako didazu ogia, mesedez? (literalmente, ‘'me pasarás el pan, por favor?'; Pasa ogia, mesedez (literalmente, 'pásame el pan, por favor').

1) orden de palabras en la oración: en vasco, la norma dice que el foco ha de ocupar la posición inmediatamente preverbal. En la lengua hablada podemos encontrar ejemplos del orden focalizador castellano, postverbal. Ejemplo: Badakizu nor naizen? (...) Ni naiz Antigua Piperra7 (en lugar de Ni Antigua Piperra naiz).

7 «¿Sabes quién soy? Yo soy Antigua Piperra». Kirmen Uribe, Bilbao-New York-Bilbao, Elkar, 2008, 110. 
m) uso de la marca de caso absoluto $(\varnothing)$ en lugar de la de ergativo $(-k)$. Es esta una de las interferencias más importantes. El hecho de que en español sujeto y agente no tengan marca distinta (tienen marca $\emptyset$ ) hace que muchos neovascohablantes no incluyan en el agente el sufijo ergativo (*Koldo jakingo du hori, en lugar de Koldok jakingo du hori 'eso lo sabrá Koldo). La ausencia de dicho sufijo hace que haya dos sintagmas (Koldo y hori 'eso') con marca de caso absoluto (cuando no puede haber dos argumentos con el mismo papel temático) y ninguno con marca de ergativo, cuando el verbo nos indica que ha de haber un agente singular y un tema (objeto directo) singular. El ejemplo, pues, resulta ininterpretable desde un punto de vista inmanente de la lengua vasca, pero no en una situación de lenguas en contacto como esta en la que nos encontramos. La corrección del error de omisión de la marca de ergativo es una de las principales tareas de los enseñantes de vasco. Por ello, no ha de extrañarnos que Ur Apalategi, en su cuento «Ergatibu» (mezcla de las palabras vascas ergatibo y gatibu 'cautivo'), incluido en Fikzioaren izterrak ('Los muslos de la ficción', Susa, 2010), aproveche la circunstancia con fines humorísticos. El protagonista no perdona a su mujer sus errores en vasco, y la omisión del ergativo menos que ningún otro:

Dena hasi zen «Idurre ez du nahi Coca-Colarik?» esaten entzun nuenean. Ez zen, noski, Nekanek ergatibo bat ahanzten zuen lehen aldia. Jakinaren gainean ezkondu nintzen ${ }^{8}$.

n) estructuras reflexivas. En vasco suelen crearse colocando como SNobjeto el sustantivo burua 'cabeza', precedido del posesivo correferencial con el agente de la oración. Ejemplo: Juan se tiró al mar se dice en vasco Jonek itsasora bota zuen bere burua (literalmente, 'Juan tiró su cabeza al mar'. Por influencia del español, muchos hablantes sustituyen la rección ABS-ERG (su cabeza-Juan, es decir, con dos valencias) por la rección ABS, interpretando el pronominal castellano se como equivalente al de verbos tales como despertarse, alejarse, etc., con una sola valencia. Ejemplo: Jon itsasora bota zen (Jon en caso absoluto y auxiliar zen de rección ABS). Esta estructura ha calado enormemente tanto en la lengua vasca oral como escrita (literatura, medios de comunicación, etc.), de modo que parece que va siendo hora de quitarle la etiqueta de agramatical.

ñ) estructuras recíprocas. En vasco se forman con el pronombre recíproco elkar, declinado según su función sintáctica. Cuando se quiere expresar el pronombre recíproco se del español, muchos hablantes (e incluso escritores) prescinden de elkar y recurren a la rección ABS (en lugar de la rección ABS-ERG, desempeñando elkar la función de objeto directo). Ejemplo: besarkatu egin ginen $^{9}$ (siendo ginen auxiliar ABS de pasado, primera persona del plural) en lugar de elkar besarkatu genuen 'nos abrazamos (siendo genuen auxiliar ABS-

8 «Todo empezó cuando la oí decir «Idurre ez du nahi Coca-Colarik?» ('Idurre no quiere Coca-Cola'), sin la marca $-k$ en Idurre. No era esa, claro está, la primera vez que Nekane olvidaba un ergativo. Me casé con ella a sabiendas», p. 128.

9 Kirmen Uribe, op. cit., 179. 
ERG). Esta interferencia también ha prendido en el vascuence oral y escrito, siendo el ejemplo aportado buena prueba de ello.

o) confusión adjetivo/adverbio. En español, el comparativo mejor puede ser tanto adjetivo como adverbio. En vasco, el primero se traduce como hobe, y el segundo como hobeto u hobeki, según el dialecto. La interferencia consiste en usar hobe en lugar de hobeto/hobeki, o usar hobeto/hobeki en lugar de hobe. Ejemplos: *Hobeto da hori (en lugar de Hobea da hori 'Es mejor eso'). *Hobe esanda (en lugar de Hobeto esanda 'Mejor dicho').

p) uso del numeral bat 'uno/una' en expresiones atributivas. Ejemplo: * $Z u$ tonto bat zara 'Tú eres un tonto'. El atributo en vasco va con artículo determinado (Zu tontoa zara), a diferencia de lo que ocurre en las lenguas de su entorno. También es incorrecta la forma plural (batzuk 'unos') para enfatizar la cualidad (*Zuek tonto batzuk zarete 'Vosotros sois unos tontos', en lugar de, por ejemplo, Zuek tonto galantak ${ }^{10}$ zarete). En singular, el uso del numeral con valor enfático también es un calco incorrecto (*Gose bat daukat... 'Tengo un hambre...').

q) el cuantificador asko no puede acompañar en vasco a sustantivos no cuantificables tales como gose 'hambre', bero 'calor', etc. Para expresar la idea de intensificación ha de recurrirse a adjetivos de ese matiz, tales como handi 'grande', luze 'largo', etc. Así pues, «mucha hambre» se dice en vasco gose handia, y no *gose asko, aunque sea la forma utilizada por muchos hablantes. En algunos casos, la expresión en principio incorrecta tiene mayor uso que la preferida por las gramáticas, tal como ocurre con el sustantivo denbora 'tiempo': denbora asko (lit. 'mucho tiempo') es mucho más frecuente que denbora luzea (lit. 'largo tiempo'). Basta para comprobarlo recurrir al buscador de Google. También resulta muy significativo el título de cierto relato de Bernardo Atxaga: Bi letter jaso nituen oso denbora gutxian ('Recibí dos letters en muy poco tiempo'). Atxaga, en oso denbora gutxian, a pesar de que denbora no es un sustantivo contable, opta por el cuantificador gutxi ('poco'), cuando la expresión gramaticalmente preferible habría sido oso denbora laburrean (literalmente, 'en un tiempo muy corto'), más gramatical, sí, pero menos usada. Además, hay que tener en cuenta que en dicho cuento es fundamental la oralidad.

r) el adjetivo posesivo de tercera persona es, para el singular, haren o bere, y para el plural haien o beren. Bere y beren se emplean cuando son anáforas de un elemento con marca en el verbo. Para anáforas de un elemento sin huella en la morfología verbal hay que recurrir a haren y haien. Los siguientes ejemplos, traducibles como «Miguel nos ha vendido su casa», pueden resultar esclarecedores:

Mikelek $_{\mathrm{i}}$ bere $_{\mathrm{i}}$ etxea saldu digu

Mikelek $_{\mathrm{i}}$ haren $_{\mathrm{j}}$ etxea saldu digu

* Mikelek $_{\mathrm{i}}$ haren $_{\mathrm{i}}$ etxea saldu digu

10 Galant 'grande' es un adjetivo enfático. 
Es decir, si se usa bere y es anáfora de Mikel, la expresión es gramatical. Si se usa haren y no es anáfora de Mikel, la expresión también es gramatical. Pero si se usa haren como anáfora de Mikel, se incurre en agramaticalidad.

s) en estructuras afirmativas, los sintagmas de caso con función de objeto directo presentan artículo determinado $(a)$, pluralizante $(k)$ y marca de caso absoluto (Ø), y en el verbo ha de ir marcada esa pluralización de objeto mediante un morfema (it o $z$ ). Sin embargo, en estructuras negativas, cuando dicho sintagma de caso tiene valor indeterminado, hay que añadirle, en lugar de $a+k+\emptyset$, el sufijo partitivo $-i k$. Ejemplo:

Sagarrak jan ditut 'He comido manzanas'. Sagar $+a+k+\emptyset$, y pluralizante it en el auxiliar ditut.

$E z$ dut sagarrik jan 'No he comido manzanas'. Sagar( $r)+i k$, y no pluralizante en el auxiliar $d u t$.

«No he comido manzanas» no puede expresarse en vasco con $« E z$ ditut sagarrak jan», que es gramatical, pero que significa «no he comido las manzanas» (es decir, el objeto es determinado).

\section{SINTAXIS COMPLEJA}

Las siguientes interferencias en sintaxis compleja han de ser definidas, simple y llanamente, como agramaticalidades:

a) uso del prefijo condicional $b a$ - en cláusulas interrogativas indirectas totales. Ejemplo: *Ez dakit joango banaiz (en vez de Ez dakit joango naizen) 'No sé si iré'. Recordemos que en las interrogativas indirectas vascas, tanto totales como parciales, al verbo subordinado hay que incorporarle el sufijo subordinante $-n$. Por su parte, en español, las interrogativas indirectas totales van introducidas por la conjunción si. Al coincidir formalmente esa conjunción con la conjunción condicional $s i$, no son pocos los vascohablantes que, en las interrogativas indirectas totales, añaden al verbo subordinado el prefijo condicional $b a-$, y no el sufijo $-n$.

b) no introducir la marca de subordinación - $n$ en cláusulas interrogativas indirectas parciales. Ejemplo: ${ }^{*}$ Ez dakit zenbat urte dituzu (en vez de Ez dakit zenbat urte dituzun) 'No sé cuántos años tienes'. Esta interferencia tiene su origen en el hecho de que tales interrogativas, en español, carecen de conjunción, y solo se distinguen de las interrogativas directas parciales por la entonación. En cambio, en vasco, tal como hemos indicado líneas más arriba, en todos los verbos de cualquier interrogativa indirecta, tanto parcial como total, hay que incluir el sufijo subordinante $-n$.

c) uso del sufijo verbal completivo - $l a$ en lugar del relativo - $n$ en cláusulas relativas apositivas. Ejemplo: *Badut txakur bat Alai izena duela (en vez de Badut txakur bat Alai izena duena) 'Tengo un perro que se llama Alai'. La interferencia se debe a la coincidencia formal, en español, de la conjunción 
completiva (que) y el pronombre relativo (que). La interferencia no se produce en relativas vascas no apositivas (es decir, las relativas canónicas), porque son ramificaciones a la izquierda del núcleo nominal (Alai izena duen txakur bat $d u t$ ). Al ser tan divergente esa estructura respecto a la del español (cuyas relativas son siempre ramificaciones a la derecha del núcleo nominal), en las relativas vascas «canónicas» los hablantes no incurren en la confusión de los sufijos verbales - la y $-n$. En cambio, las relativas apositivas vascas sí son ramificaciones a la derecha del núcleo nominal, por lo que en ellas se puede producir la confusión de ambos sufijos por influencia del español.

\section{LÉXICO}

Como apuntan, entre otros, Ibon Sarasola (1997) y Xabier Elosegi (2013), existe una gran brecha entre el léxico del vascuence hablado por vasco-españoles (con tendencia al préstamo léxico del español) y el hablado por vasco-franceses (con tendencia al préstamo léxico del francés), lo cual puede provocar dificultades en la intercomprensión. Hay, como es obvio, por razones de contacto lingüístico y diglosia, cientos de ejemplos en el vascuenzol. Veamos algunos de ellos, divididos en dos tipos: uso del léxico del español (en detrimento de las palabras vascas) y uso erróneo de léxico vasco por influencia del castellano.

\subsection{Uso del léxico castellano}

a) numerales (en precios, fechas, etc.). Ejemplos: Zenbat da? $?^{11}$ / Cuarenta y ocho. Noiz jaio zinen ${ }^{12}$ ? / Mil novecientos treinta y cuatron ${ }^{13}$. Este fenómeno se detecta en hablantes de cierta edad que no fueron escolarizados en su lengua materna (el vasco), sino en español, que por aquel entonces era la única lengua vehicular en la enseñanza.

b) uso de sufijos castellanos en compuestos. Veamos ejemplos de gentilicios y profesiones:

- gentilicios: brasileño (en lugar de brasildar); filipino (en lugar de filipinar), polako (en lugar de poloniar), etc. En ocasiones se incurre en el error de aunar en la misma palabra los dos sufijos, español y vasco. Ejemplo: *magrebiar (en lugar de magrebtar).

El uso del sufijo castellano puede suponer una diferencia de significado. Ejemplo: amerikar (natural de América; natural de EEUU) vs. amerikano (equivalente al término castellano indiano, si bien la palabra vasca no implica necesariamente enriquecimiento ${ }^{14}$ ).

\footnotetext{
11 ¿Cuánto es?

12 ¿Cuándo naciste?

$13 \mathrm{La}$ - $n$ final en cuatron es la posposición inesiva vasca - $n$, equivalente a la preposición castellana $e n$.

14 Hiztegi Batua ('Diccionario unificado') aporta la siguiente definición: «Ameriketatik (abe-
} 
- profesiones: ekonomista (en lugar de ekonomialari), politiko (en lugar de politikari), etc. La palabra politiko existe en vasco, pero como adjetivo (egoera politikoa 'situación política'), pero no como sustantivo referido a una profesión. El vasco, para las profesiones, cuenta, entre otros, con el sufijo -(l)ari.

c) uso de adjetivos y adverbios castellanos, en lugar de los correspondientes vascos (muchos de los cuales son palabras derivadas): completamente diferente (en lugar de erabat ezberdin); incomprensible (en lugar de ulertezin); políticamente (en lugar de politikoki); agradable (en lugar de atsegin); precisamente (en lugar de hain zuzen ere); perecedero (en lugar de galkor); guay; super-guay; acojonante; impresentable; etc.

d) algunos meses del año. Ejemplo: Noviembren joan nintzen ('Fui en noviembre', en lugar de Azaroan joan nintzen).

e) dobletes según el registro. Se tiende, en ocasiones, a emplear el castellanismo en la lengua oral, informal, y el neologismo (palabra derivada o compuesta) en un registro culto. Ejemplos: frigorifiko vs. hozkailu; arroz con leche vs. arrozesne.

f) expresiones hechas: al aire libre; a la intemperie; a lo que caiga; por churro; a correr; aviso para navegantes; a lo que salga.

g) palabras y expresiones referidas a ámbitos a los que hasta épocas recientes no había accedido la lengua vasca (política, universidad, etc.). Ejemplos: política pesquera común 2014-2020; turismo; medicina; farmacia; patrón de yate; artículo de lujo.

\subsection{Uso erróneo de léxico vasco por influencia del español:}

a) polisemias en un idioma aplicadas al otro. Veamos algunos ejemplos.

En vasco, aita es padre, y ama es madre. Para el plural «padres» en el sentido padre+madre hay una palabra distinta, gurasoak. Es, pues, algo similar a lo que ocurre en inglés (mother, father, parents). En español, en cambio, existen padre, madre, y un plural (padre+madre) que emplea el primer vocablo, con el morfema de plural. La interferencia en la que incurren vascohablantes con poco dominio de la lengua vasca es el uso, para el plural padre+madre, del término aitak, en lugar de gurasoak. En nuestro trabajo sobre espacuence (2013: 270) ya habíamos mencionado que aita es una palabra-barniz habitual en el español hablado en la CAV, y que se emplea la expresión mis aitas, por influencia del español, en el sentido de «mi padre y mi madre».

rasturik) itzuli den euskal herritarra» ('vasco que vuelve -enriquecido- de América'). Nótese que la palabra aberasturik ('enriquecido') aparece entre guiones. El libro de estilo del periódico Berria (2006:200) omite la referencia al enriquecimiento: «Ameriketara lanera joan eta urte batzuk igaro eta gero itzuliriko euskal herritarra» ("vasco que se va a América a trabajar y, tras unos años, regresa al País Vasco'). 
Ertzaina es un agente de la policía autónoma vasca, y dicho cuerpo se denomina Ertzaintza. Debido a que la palabra española policía abarca los dos significados (agente y cuerpo), hay quienes utilizan la palabra ertzaina en el sentido de Ertzaintza, y la palabra Ertzaintza en el sentido de ertzaina. Al tratarse igualmente de palabras-barniz del espacuence, también en este se comete dicho error, igualmente detectable, incluso, en algunos coches-patrulla de la Ertzaintza, en los cuales podemos leer el rótulo Ertzaina.

El verbo ospatu ('celebrar') se circunscribe a actos festivos. Por tanto, su uso es incorrecto cuando se vincula a congresos, reuniones, etc.

Es incorrecto el uso de los sustantivos eszenatoki y eszenategi ('escenario') con valor figurado, del cual carecen. En tales contextos, ha de usarse palabras tales como egoera ('situación'). Ejemplo: *eszenatoki politikoa (en lugar de egoera politikoa).

b) la lengua española abusa de los sustantivos abstractos. En vasco se tiende a sustituirlos, en la medida de lo posible, por nominalizaciones verbales. Ejemplo: Ebakuntza egiten badiote ere, eskuaren mugikortasunean arazoak izango ditu 'Aunque le operen, tendrá problemas en la movilidad de la mano' (ejemplo extraído del periódico Euskaldunon Egunkaria). La mayoría de correctores de textos habrían sustituido ese enunciado por este otro: Ebakuntza egiten badiote, eskua mugitzeko arazoak izango ditu (literalmente, 'aunque le operen, tendrá problemas para mover la mano'). Aquí se ha empleado el verbo mugitu 'mover' en lugar del sustantivo abstracto, de él derivado, mugikortasun 'movilidad'. No obstante, hay que matizar que en determinados tipos de texto (científicos, jurídicos, filosóficos, etc.) escritos en lengua vasca no se puede prescindir, como es lógico, de los sustantivos abstractos, ya sean préstamos o palabras derivadas.

c) uso incorrecto de algunos sufijos. Un ejemplo archiconocido es el sufijo -pen en el barbarismo diputapen. -Pen es sufijo derivativo que convierte un verbo en sustantivo abstracto (sentitu 'sentir' > sentipen 'sensación'). Algunos neo-vascohablantes establecen una identificación de dicho sufijo con el sufijo castellano -ción, pero en realidad solo es parcial, ya que -ción en ocasiones no se une a bases verbales, tal como ocurre con el sustantivo diputación. La interferencia se produce, precisamente, con ese término, cuando algunos vascohablantes creen que el equivalente vasco es *diputapen ${ }^{15}$, en lugar de diputazio (préstamo) o aldundi (neologismo, palabra derivada), vocablos correctos ${ }^{16}$. En el mismo sentido, es erróneo el término *oposaketa ('oposición'). -Keta es sufijo nominalizador, pero el verbo oposatu no existe. En este caso, hay que recurrir al préstamo total, tanto en el lexema como en el morfema (oposizio).

15 Es un neologismo incorrecto porque no existe el verbo diputatu (ni tampoco en español diputar). Diputatu es, en vasco, un sustantivo ('diputado').

16 Además, *diputapen tiene la agravante de que, acompañado del artículo (-a), evoca una expresión malsonante castellana, por lo que no son pocas las bromas que se suelen gastar a su costa. 
d) formación incorrecta de palabras compuestas. Ejemplo: *laburmetraia (literalmente, 'cortometraje'). En vasco, el adjetivo aparece pospuesto al nombre. Por tanto, lo correcto es film labur (lit. 'película corta').

e) traducción literal de fraseología castellana. Ejemplos: *guardia jaitsi 'bajar la guardia' (en lugar de, por ejemplo, erne egoteari utzi, literalmente, 'dejar de estar atento'); *ilea hartu 'tomar el pelo' (en lugar de adarra jo), etc. Hay cientos de ejemplos, muchos de los cuales han sido comúnmente aceptados, tales como kolperik jo gabe 'sin dar ni golpe'. No obstante, habría que preguntar a un vasco-francés si entiende dicha expresión. En efecto, la traducción literal de fraseología castellana/francesa ha acentuado la brecha entre la lengua vasca de la VP y la de la VC.

\section{ALTERNANCIA DE CÓDIGOS}

El cambio o alternancia de códigos ${ }^{17}$ (en inglés, code-switching) es muy frecuente en situaciones de bilingüismo, sobre todo si son diglósicas. No es, pues, de extrañar, su frecuente uso en el vascuenzol ni, en consecuencia, la abundante bibliografía publicada al respecto. No hay que olvidar, por ejemplo, que muchos niños vascos que reciben la enseñanza primaria en el modelo D (con el vascuence como lengua vehicular) tienen el español como lengua materna. Y que, por dar un segundo ejemplo, muchos vascohablantes de cierta edad que tienen el vasco como lengua materna recibieron, por razones históricopolíticas bien conocidas, toda su enseñanza en español.

Como decíamos en la introducción de este artículo, la alternancia de códigos, a diferencia del mero préstamo, no solo tiene carácter léxico, sino también consecuencias morfológicas y sintácticas, tales como la incorporación al discurso en una lengua de sintagmas u oraciones completos en otro idioma.

La alternancia de códigos tiene múltiples funciones (expresividad, paliar carencias lingüísticas en un idioma, etc. ${ }^{18}$ ), y, en el caso del vascuenzol, responde a la situación de diglosia que sufre la lengua vasca, como lo prueba el hecho de que, en la dirección contraria (es decir, en el espacuence), apenas encontramos alternancia de códigos, sino mero préstamo léxico, que en la mayoría de los casos puede denominarse «palabra-barniz».

Gumperz (1982) estableció una tipología de seis funciones de la alternancia de códigos:

a) citas.

b) especificación del destinatario del mensaje.

17 Lo podemos definir como el hecho de que un hablante intercale un idioma en un discurso que realiza en otro idioma.

18 Un ejemplo paradigmático de la alternancia de códigos con función expresiva (en este caso, humorística), es el programa de ETB1 «Kontuz, atsuak» («Cuidado, que vienen las viejas»). 

nantes.

c) interjecciones, muletillas, elementos discursivos y expresiones malso-

d) reiteraciones.

e) calificación del mensaje.

f) personalización u objetivación, es decir, que supone una implicación personal.

La alternancia de códigos se divide, según Poplack (1980), en tres tipos: tag-switching (tipo etiqueta), intrasentential code-switching (intraoracional) e intersentential code-switching (interoracional):

a) cambios de etiqueta (equivalente a la tercera función mencionada por Gumperz): interjecciones, muletillas, etc. Ejemplo: En principio; Porque...; Ya que...; Porque ... -lako ${ }^{19}$; Aunque...; Porque aunque...; En fin...; O sea que...; Es que...

b) intraoracional: cambiar de lengua dentro de una misma oración. Ejemplo: Hori izan zen... completamente diferente 'Eso fue totalmente diferente'.

c) interoracional: alternancia de oraciones completas en una y otra lengua. Por ejemplo, en el estilo directo, si uno reproduce más o menos literalmente un discurso que fue dicho en español, lo hará también en español. De lo contrario, el interlocutor pensará que esas palabras, originalmente, fueron pronunciadas en vasco. Ejemplo:

Esaten eustan ${ }^{20}$ : «Tiene que beber Vd. por lo menos dos litros de agua al día».

Eta nik erantzun ${ }^{21}:$ «Pues no puedo. ¿Yo tengo que beber dos litros al día?»

Eta berak $^{22}: \ll$ Procure Vd».

Como explica Orreaga Ibarra (2011: 3), la alternancia de códigos es habitual entre los jóvenes vascohablantes (sobre todo, y por muy sorprendente que parezca, entre aquellos que tienen el vasco como lengua materna), los cuales incorporan a sus conversaciones (cara a cara o a través del whatsapp y las redes sociales), sintagmas y oraciones en español.

Hay que señalar que, en el registro oral, el lenguaje juvenil se caracteriza por una expresión que huye de convencionalismos. Busca la inmediatez, la naturalidad y la espontaneidad, aunque esto lleve a salpicar el discurso de expresiones que muestran interferencias y calcos del español.

Un ejemplo paradigmático de alternancia de códigos es José Luis Korta, uno de los iconos del deporte vasco (en concreto, de las regatas de traineras). Korta, siempre vehemente, recurre a expresiones del español cuando está enojado, cosa que ocurre a menudo. Los siguientes ejemplos han sido extraídos de

\footnotetext{
19 -Lako es un sufijo verbal con significado, entre otros, causal.

20 Me dijo.

$21 \quad$ Y yo le respondí.

22 Y él (me dijo).
} 
una entrevista que el 11 de julio de 2012 le hizo Manu Maritxalar en el programa Tostartean, de Euskadi Irratia: muy bien, ijo!; bueno; claro; no me jodas; como que no; acojonante; vale; era un circo; que son chorizos; que no tienen cojones para ganar en las mismas condiciones que los demás; son amiguitos; golpe de estado; se reúnen y lo que les interesa; los históricos. Todo ello, inserto en un vasco perfectamente gramatical.

En la literatura vasca hay autores que, impulsados por el deseo de crear un efecto de realismo, recurren a la alternancia de códigos. Lo comprobaremos en el apartado siguiente.

\section{Apéndice (ejemplos de alternancia de códigos)}

Ejemplo del siglo XVIII: Acto para la Nochebuena, tragicomedia, obra de teatro popular de Pedro Ignacio Barrutia, escribano en Mondragón entre 1711 y 1752. En ella se rememoran los misterios de la Navidad: casamiento de María y José, negativa de hospedaje, nacimiento de Jesús, etc. El vasco es lengua predominante, aunque a veces hay alternancia de códigos, del que ofrecemos aquí un par de ejemplos: «Emon, emon! tiene lindo barrigón»; «No se hizo para los asnos estimakaz dulzea». Esto es típico en un sinfín de canciones y versos populares, para crear efecto cómico y expresivo. He aquí un ejemplo, a saber, la canción Din don, de Cruz Alberdi: Mi tío procurador / mi padre alkate / mis hermanas maestras / conmigo cásate. / Ai! Mírame, gaxua! / Erantzun ezazute / zertarako hoiekin / ezkontzen zerate? ${ }^{23}$.

Ejemplo de principios del siglo XX. Garoa ('El helecho', 1907), novela de Domingo de Aguirre (1864-1920), nacido en Ondarroa (Vizcaya). En algún diálogo se detecta alternancia de códigos. El ejemplo pertenece al capítulo XIX.

«Bejondaigula! —esaten du bigarren iztunlea jaikitzean-. Au dek obea, au! Sobresaliente en la facultad de Arantzadi! Doctor por la Universidad de Upelondo! Entzun bear zaio sermoia, ederra izango data» ${ }^{24}$.

Ejemplo de principios del siglo XXI: Martutene, novela de Ramon Saizarbitoria (Erein, 2012). Saizarbitoria distingue el estilo directo (en el que respeta la lengua del discurso) del discurso indirecto (expresado en vasco, sea cual sea la lengua del discurso). Veamos algunos ejemplos:

Lekuz kanpo egongo zela erantzun zion, gaztelaniaz, distantzia gehiago markatzeko «No pinto nada», eta hark «Lo mismo que otros» $(\ldots)^{25}$.

23 Mi tío procurador / mi padre alcalde / mis hermanas maestras / conmigo cásate. / ;Ay! ¡Mírame, pobre! / ¡Responded! / ¿Para qué / os casáis con esos?.

24 «QQue suerte! - dice al ver levantarse al segundo orador- ¡ ¡Este es mucho mejor! Sobresaliente en la facultad de Aranzadi! Doctor por la Universidad de Upelondo! Hay que oírle el sermón, que va a ser hermoso».

25 Le respondió que estaría fuera de juego, en castellano, para marcar más las distancias ( «No pinto nada»), y ella: «Lo mismo que otros» (...) 
Sabairantz jaso ditu besoak, eskuak bat eginda. Gracias Virgencita de las Mercedes. Mesedeetako Ama Birjina Errepublika Dominikarreko zaindaria dela argitu $\operatorname{dio}^{26}$.

Beraz, analitika eskatzea besterik ez duela egin esan dio, bera dela osasuntsu eta sasoiko eta mardul dagoena. ¿Sana y fuerte? Eskuak aldaketan jarriz, begiak zabal irekita, zuriturik ia, eta azentua karikaturaraino azpimarratuz. ¿Qué me quiere decir el doctor con sana y fuerte -eta Abaituak buruko zapi orintsu koloratua ikusi dio orain korapiloaren bi hegal luzeak kopetan tente-, que estoy gorda? ${ }^{27}$

Asimismo, en dicha novela también encontramos ejemplos de cambio de código interoracional. He aquí un ejemplo: «Chica, qué pesada eres. Ez al dun ikusten beste kontu batean nagoela? $\gg^{28}$.

\section{Ejemplo de Xabier Mendiguren Elizegi. Texto extraido de Sakoneta} (Elkar, 2011)

- Jo, tia, mugitu, berandu gabiltzala.

- Jope, Uxu, bazkaldu gabe nagoela.

- Baina zertan egon zara orain arte?

- Zertan egongo nintzen ba? Ilea garbitzen.

- Jo, tia, ya te vale.

- Markelek txima zikinekin ikusteko, ezta?

- Ba, barkatu esatea baina, Markelen txukundadea ere.

Neska biek barreari eman diote, eta barre lasai horrek baretu dizkie nerbioak ere.

- Bueno, zer eraman behar dugu? -galdetu du Naiarak, beren onera etorri direnean. -Ba, Ainhok dio denetik eraman behar dela, gerrara bezala.

- Gerrara? -Bueno, oporretan bezala.

- Ba nik datorren astean joan behar nuen oporretara.

- A, bai? Nora?

- Ba, Amagoia eta biok goaz. Hasieran Marokora joan behar genuen. Pixka bat Marrakex eta Fez, eta gero Atlas aldera.

26 Ha alzado los brazos hacia el techo, juntando las manos. Gracias, Virgencita de las Mercedes. Dice que la Virgen de las Mercedes es la protectora de la República Dominicana.

27 Por tanto, le ha dicho que no ha hecho más que pedir una analítica, que es ella la que está sana, en forma y lozana. ¿Sana y fuerte? Con las manos en las caderas y los ojos bien abiertos, casi en blanco, y subrayando el acento hasta la caricatura. ¿Qué me quiere decir el doctor con sana $y$ fuerte -y Abaitua le ha visto ahora un pañuelo para el pelo con lunares de colores, con las dos largas alas del nudo tiesas en la frente-, que estoy gorda?

28 ¿No ves que estoy con otro asunto? 
- Ya, askoz autentikoagoa.

- Baina nola Amagoiari-eta lantokia itxi dieten, txakur txikirik gabe dago, eta hortaz, Pirinioetara goaz, Huescako partera, kanpinean.

- Jo, ba, dabuten, tia.

- Bueno, ondo pasatzen saiatuko gara.

- Ba ni, tia, ni bai nagoela sin una puta pela. Lehen deitzen zidaten handik eta hemendik, ordezkapenak egiteko eta hola, baina orain

- Ba, etorri gurekin.

- Ya, baina datorren astean Sanferminak dira.

- Egia. -Eta Sanferminak galtzea...

- Klaro.

- Bestela, gustura joango nintzen zuekin. Ze, nire zaharrek daukate un rollo más chungo! Lehen Saloura joaten ziren, baina urte batean, nola peña guztia etxera ekarri nuen, eta gero bizilagunek esanda enteratu ziren, ba orain ez dira joaten.

- Ze kabroiak.

- Ya te digo.

- Ta orduan, zer eramango dugu?

- Ba, oporretarako prestatuta daukazun guztia.

- Gitarra ere bai?

- Bai, bai, de puta madre, tia.

- Baina jotzeko aukerarik edukiko dugu, ala?

- Jo, ba, ez dakit, baina ondo egongo zen, ezta? Pentsa, han, sutondoan, denak bilduta.

- Eta Markel entzuten.

- Hori, hori... -eta barreari eman diote bi lagunek ostera ere ${ }^{29}$.

29 - Jo, tía, muévete, que se nos ha hecho tarde.

- Jope, Uxu, que aún no he comido.

- Pero ¿qué has estado haciendo hasta ahora? -¿Qué iba a hacer? Lavarme el pelo.

- Jo, tía, ya te vale.

- Para que Markel te vea con las greñas sucias, ¿verdad?

- Pues, perdona que te diga, pero Markel tampoco es un ejemplo de aseo...

Las dos chicas se han puesto a reír, y esa risa tranquila les ha templado los nervios.

- Bueno, ¿qué tenemos que llevar? -pregunta Naiara cuando se han serenado.

- Pues Ainho dice que hay que llevar de todo, como a la guerra.

- ¿A la guerra?

- Bueno, como en vacaciones.

- Pues yo la semana que viene tenía que irme de vacaciones.

- ¿A, sí? ¿Y adónde?

- Pues, nos vamos Amagoia y yo. Al principio íbamos a ir a Marruecos. Un poco Marrakech y Fez, y luego a la zona del Atlas. 
Ejemplos de alternancia de códigos del programa de humor Kontuz, atsuak, de ETB1 (capítulo dedicado a las elecciones):

- Algunos son del tipo «cambio de etiqueta»: ;qué va!

- Muchos responden al cambio de código intraoracional: hirurak gaude en el mismo barco 'las tres estamos en el mismo barco'; uno pa'ella eta bestea neretzat 'uno pa'ella y el otro para mí'; mucha poza 'mucha alegría'; partido-horquilla izango gera 'seremos partido-horquilla'; zer zara gehio, de Sergio Dalma? '¿qué eres más, de Sergio Dalma?; gu gea «la horquilla» 'nosotras somos la horquilla'; hau zer da, de interior o de exterior? '¿esta qué es, de interior o de exterior?

- Otros muchos son cambio de código interoracional (nótese que la mayoría son oraciones exclamativas y fraseología, lo cual coincide con la función expresiva de la alternancia de códigos): qué descarada; chicas con tirón; lo primero es lo primero; ya está; por ti no pasan los años, ¿eh?; es que nos pilla el toro; como un grifo, chica; se te va a caer el pelo; ;ay, amiga, la crisis!; ;qué chollo, chica!; no se hable más; compórtate; qué asco; lo normal; lo pide la sociedad; estamos indignadas.

\section{CONCLUSIONES}

Por razones que a nadie se le escapan, la impronta del español en la lengua vasca es mucho mayor que la de esta en aquel. No importa que no haya entre ambas lenguas relación genética. Al estar en contacto, dada la permeabilidad

- Ya, mucho más auténtico.

- Pero como han cerrado la fábrica de Amagoia, está sin blanca, así que nos vamos a Pirineos, a la parte de Huesca, de camping.

- Jo, pues, dabuten, tía.

- Bueno, intentaremos pasarlo bien.

- Pues yo, tía, sí que estoy sin una puta pela. Antes me llamaban de aquí y de allá para hacer sustituciones y tal, pero ahora...

- Pues vente con nosotras.

- Ya, pero la semana que viene son los Sanfermines.

- Es verdad.

- Y perdérselos...-Claro.

- Si no, iría encantada con vosotras, porque ¡mis viejos tienen un rollo más chungo! Antes iban a Salou, pero un año, como traje a casa a toda la peña, y luego se enteraron por los vecinos, pues ahora no van.

- Qué cabrones.

- Ya te digo.

- Y, entonces, ¿qué vamos a llevar?

- Pues todo lo que tengas preparado para las vacaciones.

- ¿También la guitarra?

- Sí, sí, de puta madre, tía.

- Pero, ¿vamos a poder tocar?

- Jo, pues no lo sé, pero estaría bien, ¿verdad? Imagínate, allí, junto al fuego, todos juntos.

- Y escuchando a Markel.

- Eso, eso... -y las dos amigas han vuelto a reírse. 
del vascuence (como la de cualquier otro idioma, dicho sea de paso), y teniendo en cuenta que todos los vascohablantes de la VP también saben español, lengua dominante, es lógico que se produzca un sinfín de interferencias en la dirección español $\rightarrow$ vascuence en todos los niveles de lengua. El calco léxico y la alternancia de códigos son los más notorios a primera vista (sobre todo para quienes no saben vasco), pero en los ámbitos fonético y morfo-sintáctico se detectan muchas otras interferencias a las que ha contribuido la gran cantidad de castellano-hablantes que han aprendido vasco durante las últimas décadas. El cambio de perfil del bilingüe (en el pasado la mayoría tenía el vasco como lengua materna, tendencia que se ha invertido en los últimos años con el proceso de euskaldunización) es un factor determinante a este respecto.

\section{BIBLIOGRAFÍA}

Altube, S. (1929) Erderismos. Bermeo, Gaubeka.

Aurrekoetxea, G. + Unamuno, L. (2011) «Perpaus arteko euskara-gaztelania kode-aldaketa», Euskalingua, 19 pp. 25-30. Disponible en http://www. mendebalde.com/modulos/usuariosFtp/conexion/archi508A.pdf

Berria (2006) Berria estilo liburua, Euskal Editorea, S. L. Disponible en Internet: http://www.berria.info/estiloliburua/

Cid Abasolo, K. (2013) «Hibridismo lingüístico en la Vasconia peninsular: sustrato vasco en el español», Revista de lenguas y literaturas catalana, gallega y vasca, 18, UNED, pp. 263-282. Disponible en Internet: http://e-spacio.uned.es/fez/eserv.php?pid=bibliuned: Llcgv201318-7065\&dsID=Documento.pdf

Epelde, I. + Oyharçabal B. (2009) «Code switching en las variedades orientales del vasco»», artc. 00389939, v1. Disponible en: http://artxiker.ccsd.cnrs. fr/docs/00/38/99/39/PDF/Epelde_Oyharcabal_panel_sociolinguistica.pdf. Reedición en: Modos y formas de la comunicación humana (coord. Caballero Rodríguez M. R. + Pinar Sanz M. J.), vol.2, 2010, pp. 609-618.

Etxabe, M. A. (1992) Hizkuntza aukeraketa edo 'code switching'a euskaldunen artean, corpus inédito euskera/español.

Etxebarria M. (1998) «Bilingüismo y code-switching en el País Vasco»», Las lenguas en la Europa Comunitaria II, Amsterdam/ Atlanta: Rodopi, pp. 55-66.

Etxebarria M. (2004) «Español y Euskera en contacto: Resultados Lingüísticos», Revista Internacional de Lingüística Iberoamericana, II, 2 (4): pp. 131-145.

Ezeizabarrena M. J. + Manterola, J. (2005) «La mezcla de códigos (euskeracastellano) en el habla infantil», Perspectivas interdisciplinares de la lingüística aplicada (coord. Carrió Pastor M. L. ), vol. 1, pp. 187-202.

Garate, G. (1988) Erderakadak, Bilbao, Mensajero.

Garzia, J. (2005) Kalko okerrak, Servicio General de Publicaciones del Gobierno Vasco, Vitoria. Disponible en Internet: http://www.hezkuntza.ejgv. 
euskadi.net/r43-573/eu/contenidos/informacion/dih/eu_5490/adjuntos/ estilo_liburua/KALKOAK/AURKIBID.pdf

Gumperz, J. J. (1982) Discourse Strategies, Cambridge, Cambridge University Press.

Hualde, J. I. 993) «Phonologically unmotivated changes in language contact: Spanish borrowings in Basque», Folia Linguistica, 27, pp. 1-25.

Ibarra, O. (2011) «Sobre estrategias discursivas de los jóvenes vascohablantes: causas que motivan el cambio de código», Oihenart, 26, 2011, pp. 277298. Disponible en Internet: http://www.euskomedia.org/PDFAnlt/literatura/26/26277298.pdf

Lantto, H. (2012) «Code-switching, swearing and slang: the colloquial register of Basque in Greater Bilbao», International Journal of Bilingualism, 16 (3).

- (2012) «Grammatical code-switching patterns of early and late BasqueSpanish bilinguals», Sociolinguistic Studies, Vol 6, No 1, pp. 21-43.

Muñoa Barredo, I. (1997) «Pragmatic functions of code-switching among basque-spanish bilinguals», Actas del I Simposio internacional sobre Bilingüismo, Universidad de Vigo, pp. 528-541. Disponible en Internet: http:// webs.uvigo.es/ss1/actas 1997/04/Munhoa.pdf

Poplack, S. (1980) «Sometimes I'll start a sentence in Spanish y termino en español: toward a typology of code-switching», Linguistics 18, 7/8, pp. 581-618.

Rotaetxe, K. (1991) «Descriptions et valeurs pragmatiques de l'alternance basque et espagnol», European Science Foundation-Scientific NetworksPapers on Code-Switching and Language Contact, Strasbourg, pp. 227-247.

- (1994) «Alternance codique et langue minoritaire», en Martel, P. + Maurais, J. (eds.): Mélanges offerts a J. C. Corbeil: Langues et Sociétés en contact, Tübingen, Max Niemeyer Versalg, pp. 395-408.

Sarasola, I. (1997) Euskara batuaren ajeak, Irún, Alberdania.

Sarrionandia B. (1992) Kode alternantzia edo 'Code-switching': hiztun euskaldunduen arteko komunikazio estrategien tipologia batetarantz, corpus inédito euskera/español.

\section{REFERENCIAS DISPONIBLES SOLO EN INTERNET}

Elosegi Aldasoro, X. (2013) «Euskara batua Iparraldetik (I)», 31 eskutik, http://31eskutik.com/2013/05/26/euskara-batua-iparraldetik-i/

Euskaltzaindia (Real Academia de la Lengua Vasca): Hiztegi Batua, http://www. euskaltzaindia.net/index.php?option=com_hiztegianbilatu\&view=frontpage \&Itemid=410\&lang=eu

SEG (SAREKO EUSKAL GRAMATIKA), http://www.ehu.es/ehg/kalkoak/ 